mansasa

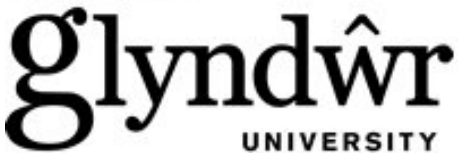

Glyndŵr University

Glyndŵr University Research Online

Social Inclusion Research Unit

Social and Community

$1-1-2003$

\title{
Menopause, sexuality and culture: Is there a universal experience?
}

Edna M. Astbury-Ward

Glyndwr University, e.astbury-ward@chester.ac.uk

Follow this and additional works at: http://epubs.glyndwr.ac.uk/siru

Part of the Family Practice Nursing Commons, Gender and Sexuality Commons, Medicine and Health Commons, Nursing Midwifery Commons, Other Nursing Commons, and the Public Health and Community Nursing Commons

Copyright (C 2009 Routledge Taylor and Francis. This is an electronic version of an article published in Astbury-Ward, E. (2003) 'Menopause, sexuality and culture: Is there a universal experience? Sexual and Relationship Therapy'.Journal of the British Association for Sexual and Relationship Therapy. 18(4),437-445. The published version is available online at http://www.tandfonline.com/ doi/abs/10.1080/14681990310001609787

\section{Recommended Citation}

Astbury-Ward, E. (2003) 'Menopause, sexuality and culture: Is there a universal experience? Sexual and Relationship Therapy'. Journal of the British Association for Sexual and Relationship Therapy. 18(4), 437-445

This Article is brought to you for free and open access by the Social and Community at Glyndŵr University Research Online. It has been accepted for inclusion in Social Inclusion Research Unit by an authorized administrator of Glyndŵr University Research Online. For more information, please 


\section{Menopause, Sexuality and Culture: Is there a universal experience?}

Correspondence Address July 2011

Dr. Edna Astbury-Ward.PhD, M.Sc, RGN, Dip. H. Ed

Sessional Lecturer Nursing (Leadership \& Transformation of Care)

Institute of Health, Medical Sciences \& Society

Visiting Research Fellow at Social Inclusion Research Unit

Glyndwr University

Mold Road

Wrexham,

Wales.

LL11 2AW. 


\title{
Menopause, Sexuality and Culture: Is there a universal experience?
}

\begin{abstract}
$\underline{\text { Abstract }}$
Menopause is a universal phenomenon, but do all women experience a universal event? The aim of this article is to identify common trends or patterns occurring exclusively within certain different cultures, and whether these have an effect on how menopause is experienced or perceived by those women. This paper will first consider the physiological changes that occur during menopause and will then look at psychosocial influences that may affect women's perception and experience of menopause.
\end{abstract}

During menopause although physiological changes certainly do take place, cultural values may determine whether these changes signify improvement or decline, or are inconsequential. Ageing involves beliefs, attitudes and practices. In our society, these rituals of ageing are often assumed to be normal, natural, formed mainly from common sense and largely unalterable, although it is easy to think of many examples to the contrary.

The social construction of menopause as the entry point to old age may represent a challenging and difficult time, because while women may feel young, society tends to perceive them as rather less attractive and less fully functioning. This perception of menopause as a negative milestone is often found only in Western cultures. Medical culture also influences the meanings of middle and old age, particularly for women at the time of approaching menopause. 
Cultural bias against ageing and sexuality has contributed to that stereotyping of older women as asexual. In general, the media has not served the ageing female well. Older men are often marketed as sexy, yet older women are rarely seen outside of advertisements for hormone replacement therapy (HRT) and Conti knickers.

Health care workers are just as subject as others to ideological or denigrating constructions of old age, and the consequences of holding these images in our minds may well influence the choice of care and treatment that we give to the older person. Few of us are as sensitive to the rights of others, as we are to immediate pressures to conform to existing procedures or to the needs of cost and efficiency (Mangum 1999).

This paper will look critically at:

- the process of menopause and the effects on the woman's body and mind;

- $\quad$ psychosocial influences of culture and how they may affect the individual;

- $\quad$ female sexuality and how it relates to the menopause;

- $\quad$ the published literature.

The following electronic methods: Medline, CINAHL, Science Direct, BIOMED and BIDS and hand-searches were used. 


\section{Definition of menopause}

Menopause is a universal female midlife transition associated with the ageing process. It is variously defined in a number of different texts as "an oestrogen deficiency disease"

(Hunter 1996, Klein et al 1999, Riley 1991), but Hunter and Riley stress the dangers and limitations of defining menopause as this alone. Riley (1991) acknowledges that "some but not all, sexual problems can be explained in terms of changes resulting from oestrogen deficiency. Psychological and behavioural disturbances may also contribute at this time." Hunter outlines the "implications for the way middle aged and older women's views and behaviours are perceived in society".

Opinions differ over exactly when menopause begins. Some of the epidemiological studies use cessation of menses as the beginning of menopause and ignore the perimenopause (McPherson and Waller 1997, Nicol-Smith 1996). However, the perimenopausal state may begin years before amenorrhoea with somatic symptoms (Klein et al 1999). Nicol-Smith argues, that the generally accepted research definition of the menopause as the final menstruation "is unhelpful" because it makes it difficult to construct categories for data analysis.

The menopause is traditionally viewed as the time when a woman passes from reproductive to non- reproductive phases (Riley 1991), or from ovulatory to anovulatory changes (Klein et al 1999). The start of menopause can provide a profound sense of 
liberation for some women (freedom from menstruation and the possibility of pregnancy), while in others there may be a decline in the woman's sense of self as a reproductive being. Both biological and psychosocial factors are likely to influence these emotions.

The average age for the menopause in the West is 51 years (Riley 1991), or just over 50 and remarkably constant (McPherson and Waller 1997). Others have reported similar findings (Bancroft 1989, Macleod 1984, Watson 1979).

Women's life expectancy is now in excess of 80 years (Riley 1991) in at least 35 countries (WHO 2000), and 12 million women in the UK are aged over 45 (Vincent 2001), 198 million women over the age of 60 are living in developing nations, and 135 million are in developed regions (WHO 2000).

\section{Organic changes associated with pre-, peri- and post-menopausal women}

For the purpose of this paper menopause is defined, as meaning the natural menopause resulting from the gradual loss of ovarian follicular activity, as opposed to the surgical or induced menopause, which is brought about artificially by removal of both ovaries (with or without hysterectomy) or other ablation of ovarian function (e.g., chemotherapy, radiation, etc.).

The most significant physiological change that occurs at the time of menopause is the fluctuation in the levels of circulating hormones, particularly oestrogen. The ovary prior to menopause produces significant amounts of oestrogen in response to the stimulating 
effect of the gonadotrophins, follicle stimulating hormone (FSH) and lutenising hormone (LH), which is secreted by the anterior lobe of the pituitary gland. This balance is maintained in pre-menopausal women by the positive and negative feedback mechanism that works between the ovaries, pituitary gland and possibly the hypothalamus. With increasing age, the ovary becomes less sensitive to circulating levels of gonadotrophins; "it becomes progressively resistant to the stimulating effects of FSH resulting in reduced oestrogen production" (Bancroft 1989, Riley 1991). Riley adds that specific symptoms can occur as a result of oestrogen deficiency, but not all menopausal symptoms are directly attributable to this.

Physiological symptoms experienced due to declining oestrogen levels have been reported in various texts (Berman and Goldstein 2001, Butcher 1999, Hunter 1996, Nicol-Smith 1996, Masters and Johnson 1966, Riley 1991, Weijmar et al 1991) Vaginal dryness is a frequent complaint of menopausal women. The formation of genital lubrication is dependent on oestrogen production. During sexual arousal, the vaginal epithelium secretes a highly viscous solution by a process of transudation (seeping), the purpose of which is to aid vaginal penetration. Failure of this process due to inadequate sexual stimulation, poor arousal response or lack of oestrogen will result in painful intercourse. If penetration is attempted, it may result in tears of the posterior labial commisure as a result of the labia minora being dragged into the vagina with thrusting.

I $t$ is easy to associate vaginal dryness with dyspareunia, but this is not the only cause of painful intercourse. The rate of arousal is slower in the menopausal woman, vaginal mucosa thins and loses elasticity and there is slower and less lubrication than 
premenopause. The vagina undergoes atrophic changes, including shortening and narrowing. General loss of elasticity and muscle tone of the genital and pelvic area occurs, and loss of fat from the labia minora and majora all contribute to the condition.

During menopause, many other changes are taking place as a result of falling oestrogen levels. The vasocongestive response is often slower in menopausal women. Adequate vasocongestion in the pelvic area allows engorgement of the perivaginal tissues; pelvic engorgement also protects the urethra and bladder and acts as a buffer from penile thrusting. The vasocongestive response also contributes to the lubrication response (Riley 1991). Other important vasocongestive changes may contribute to diminished pelvic blood flow secondary to atherosclerotic disease, leading to vaginal wall and clitoral smooth muscle fibrosis (Berman and Goldstein 2001), and a lack of clitoral engorgement may result in a loss of subjective awareness of arousal.

Vasomotor symptoms consist of hot flushes, night sweats and possibly palpitations, although their endocrine basis is not understood. No one hormone has been identified as the 'culprit', but it has been suggested that a change in the body thermostat (hypothalamic thermoregulatory centre) promotes heat loss (flushes and sweats). Oestrogen in sufficient doses abolishes menopausal flushes in nearly all women. The associated insomnia and fatigue that women get with night sweats also rises (Bancroft 1989). In a controlled study, exercise, cut flushes by $50 \%$, and cognitive behavioural therapy and deep breathing are other effective non-HRT treatments of flushes (McPherson and Waller 1997). 
Urinary tract symptoms and incontinence may be related to oestrogen deficiency (Bancroft 1989, Berman and Goldstein 2001)..

One of the chief problems associated with urinary incontinence and loss of sexual sensation is poor pelvic floor tone. Many post-menopausal women, and even younger multigravida women, seem to accept with dismal resignation the fact that some involuntary expulsion of urine is to be expected when they cough, sneeze, run or even laugh (stress incontinence). The question is: how much urine leakage will they accept before they seek help? As with sexual dysfunction, some women suffer in silence, too embarrassed to ask for help for fear of being regarded as freakish or dirty. McPherson and Waller (1997) wrote that "Women do not volunteer the symptom of incontinence, but welcome the chance of unburdening themselves, gaining relief from knowing that they are not the only ones to suffer and they need not be ashamed."

Much has been written about the association of disturbed or altered mood and the menopause. In the literature, there has been a dramatic change since 1980, when the diagnosis of involutional melancholia was removed from the third edition of the Diagnostic and Statistical Manual of Mental Disorders. There is now universal acceptance that menopause and depression are not related.

Nicol-Smith (1996) studied 43 epidemiological primary research articles published between 1966 and 1996, with the focus of the search being on the categories of emotion, affective symptoms, mental disorders and climacteric. She concluded that there was 
insufficient evidence at present to maintain that menopause causes depression. The author stated that mood changes had been reported after using HRT. However, the author only used one database (Medline) when conducting this search, and although she acknowledges that some element of bias may exist, she does not spell out the limitations of using certain search criteria on one database alone.

Klein (1999) states that failure to distinguish between different affective/anxiety disorders may be particularly important in therapeutic trials, and is also critical of studies that "lump all emotional symptoms in one group". He notes that the emotional changes attending the peri-menopausal state are quite diverse and may include different forms of depression. Hunter (1996) considers the linking of the menopause with depression, pervasive in the lay and medical press. She attributes this not to evidence-based research but to historical myths and menstrual taboos. She says that poor attitudes to fertility and ageing have produced an image of menopause as a time of physical and emotional decline Klein (1999) writes that women with a past history of affective/anxiety disorders in the setting of endocrine fluctuation may be particularly at risk of developing peri-menopausal affective/anxiety disorders. His plea for more carefully designed non-epidemiological studies appears justified.

In Western societies, ageing in women is not always valued, and there is a constant pressure on women to maintain a youthful appearance. This obsession with youth is demonstrated in popular culture. The absence of realistic role models with whom older 
women can identify needs to be continuously challenged if we are to prevent women becoming dissatisfied with how they look as they age. Poor body image can contribute to negative feelings, and therefore these women may be predisposed to some form of depression if they feel that they are no longer attractive to their partner. Women may also find menopause a time to reflect on the past. They may look at their past and present relationships, and their choices about children and work satisfaction. Some may regret certain decisions or have unfulfilled dreams.

While some women report feeling greatly relieved to cease menstruation (Hunter 1999), others feel a sense of loss. For women who see menstruation as a symbol of femininity and womanliness, its end may lead them to question their female identity. Other women may find it difficult to accept the loss of reproduction. Even for women who have made a well-considered decision not to have children (or any more children), the loss of capability and options may trigger deep feelings of sadness. A range of other life circumstances often occurring at midlife can impact on a woman's menopausal experience. These may include children leaving home, loss of a partner through death and separation or divorce. Another factor may be caring for elderly relatives. Sometimes the changes that illness brings affect the structure of people's relationships, and the independent person may become the carer or the cared for. This shift can alter an adult/adult relationship to parent/child relationship, and it is difficult to maintain an active sex life under these circumstances, particularly if the illness impacts on self esteem (Russell 1998). Many women may dread the thought of taking early retirement from a 
career that they have enjoyed. They may be anxious about spending more time together as a couple, and may not know what to say or how to fill the time with a partner.

The impact of disease and disability cannot be ignored when considering life events at the time of the menopause. The conditions that may have an impact on a woman's sexuality can be considered under the broad headings of physical, psychological, and treatment effects. The first group may include procedures that involve the genitalia due to gynaecological conditions and their treatments, particularly those for malignant disease. This type of treatment also affects the psychological well being of the woman. When sexuality is affected, patients can be taught to adjust and adapt to their new situations rather than accepting an end to their sexual lives. However, there is a lack of suitably trained health professionals that deal with these problems, and referring these patients may not be an option. Other non-specific conditions not related directly to the genitalia but which affect sexual function include stroke, pain, tiredness and immobility due to arthritic changes, alteration in body image, either perceived or actual. Commonly used drugs may have an effect on an individual's sexuality by decreasing libido or altering the sexual response. When considering the use of drugs, the negative effect may be outweighed by the positive effect of mood enhancement.

\section{Female sexuality and the menopause: truth or myth?}

Regarding the effects on sexuality of selective serotonin reuptake inhibitors (SSRIs), an excellent review paper by Edwards and Anderson (1999) listed 36 side effects (under system 
order) that had been noted within the first two years of the individual SSRI being marketed. Out of the 1,226,000 prescriptions written, sexual dysfunction was reported on only 177 occasions. While male sexual dysfunction was reported in the others, female sexual dysfunction was not referred to. This is a blatant example of under-reporting. A consensus view is that up to $43 \%$ of women complain of at least one sexual symptom (Basson et al 2000). James (1998) believes sexual dysfunction "is frequently suffered in silence and often accepted by both the woman and her medical adviser as untreatable".

Defining female sexuality is like defining the menopause: not without its difficulties, but unique to the individual woman. It cannot be defined by looking only at the medical model, and the psychological element to female sexuality must be addressed. Female sexual dysfunction is a multicausal and multidimensional problem combining biological, psychological and interpersonal determinants (Basson et al 2000). It has a major impact on quality of life and interpersonal relationships (James1998) and can cause marked distress and interpersonal difficulty (DSM-IV). Many dysfunctions in women are not exclusively psychologically or organically based (Basson et al 2000).

Basson argues that female sexuality differs from men's in three distinct areas: women are not driven, as men are, by their hormones; women's motivation (or willingness) to be sexual stems from a series of rewards or gains that are not strictly sexual; and "women's sexual arousal is a subjective mental excitement that may or may not be accompanied by awareness of vasocongestive changes in her genitalia." She believes that many women who are sexually functional (i.e., can respond to a partner's needs) do not have 
spontaneous sexual desire, and she considers physiological arousal to take place secondarily to the conscious decision to be sexual for one of the reasons given. Basson seems to consider that 'brain sex' is what happens initially to a woman, when she says "women are mainly speaking of mental excitement when they speak of sexual arousal"

Given all that we know (which still isn't a lot), and using Basson's 2000 model of sexual response, it is easy to understand why Western women find difficulty responding to their partners (if they have one) or maintaining any spontaneous desire for self stimulation during their menopausal years, with all the attendant life events that may be happening. Depression, loss of ovarian androgens, co- morbidity of disease and relationship conflicts contribute to an overall negative image of the Western menopausal woman.

\section{Cultural Influences and the Menopause}

It is relevant to ask if this is how the menopause is perceived in non-Western societies. Very little has been written about the mid-life experiences of women beyond Western Europe, North America and Australasia. Whilst Western women's menopause is an inexhaustible topic in the medical literature, other women's experiences are not well documented.

Does this situation also exist in other parts of the world? A manual search confirmed the paucity of published material on menopause and culture. There were a lot of medical and 
psychological books that only dealt with the bio-medical model of menopause, and a virtual absence of specific books on my search. Some of my discussion will therefore be drawn from observation, anecdotal evidence and clinical experience. Despite the burgeoning literature on ageing, the menopause and other non-reproductive aspects of women's bodies and health are poorly documented, especially given all the books on reproductive health.

The most recent and widely quoted cross-cultural study is Yewoubdar Beyene's (2000) comparison of Mayan women in Yucatan Mexico and rural Greek women on the island of Evia. She discovered that there was no word in the Mayan language to describe hot flushes and that the women did not complain of such symptoms. Bulbeck (2001) argues that whereas medicine constructs the western woman's menopause as "embodied and physical", the Asian woman experiences a status passage, a social experience made meaningful by the roles associated with it. The status of grandmother or elder confers mobility and freedom from the reins of motherhood and unwanted reproduction. There is a remarkable contrast of the symptom-free Asian woman in midlife to that of her Western counterpart bowed down by her menopausal symptoms and loss of status as she ages.

There is no word for menopause in the Chinese language, and in Chinese philosophy midlife is just an accepted part of the natural ageing process helped by the use of traditional medicines. In Japanese society, where the work ethic is strong, menopausal problems are often viewed as a luxury disease of modernity, affecting women with too much time on their hands. An interesting small study by Rice (1995) looked at the 
menopausal experiences of women of the Hmong Tribe living in Melbourne, Australia. The Hmong are from Laos in SE Asia, and they live as hill tribes in high mountainous areas. The Hmong follow ancestral worship, and they believe in reincarnation and rebirth. The traditional Hmong family is large, with boys having a particularly high social value to carry on the traditions; these traditions are still practised, even though this small cohort that was studied $(\mathrm{n}=26)$ live in Australia. Hmong girls' and adolescents' status change when they marry and have children. Giving birth brings prestige to a Hmong woman, and her status changes again when she becomes old. They are referred to as respected elders. Because menopause is associated with ageing, post-menopausal Hmong women gain respect and a higher status than when they were young.

In the Hmong language, there is no equivalent word for menopause. Menopause is seen as the consequence of transition from fertility to infertility. All the postmenopausal women in the study $(\mathrm{n}=9)$ had their menopause at a mean age of 43 years (Beyene also noted that Mayan women were already postmenopausal in their early 40s, attributing this to poor nutritional status). Because of this, some women regretted no longer being able to bear children, even though they had already had large families, but this was the only negative aspect they saw to menopause. When the women were asked about physical changes that occurred during menopause, they only reported irregular and lighter menstruation. Women were asked about emotional changes or difficulties, again no symptoms were reported, and they found it amusing that this was not the case with Western women. 
Hmong women had a positive attitude and a positive experience of the menopause. Is this because the Hmong value age over youth? Similar findings have been reported by Kaufert's 1982 study of Indian women of the Rajput caste in the states of Rajistan and Himachal Pradesh, but unfortunately the specific issue of sex and sexuality were not addressed in these studies. This may have been because of strict cultural taboos that prevented discussion of the topic, or the researchers might have felt that even if the question were asked, they would be unlikely to get an honest reply.

\section{$\underline{\text { Discussion }}$}

Although there are some small studies of interest from a sociological and anthropological standpoint, there is still no real physiological evidence to suggest strongly that women do not experience the same symptoms universally, or that they do. Available evidence suggests, however, that the menopause, as well as being a biological event, is also a social construction and that attitudes and expectations are influenced by the society. A woman's individual response to the menopause is similar to her response to sexual arousal: external factors may influence her subjective experience of it. Positive rewards and gains that society bestows upon the woman at menopause seem to have an influence over how she perceives what she is experiencing. To revisit Basson's 2000 model of female sexuality, it is argued that women have sex for reasons of non-sexual rewards and gains that are important to that woman; if as a result of that sexual encounter the woman gets those rewards and gains, then she will view the sexual encounter as a positive experience. We can look at the attitude to the menopause in much the same way. If as a 
result of the menopause women gain a positive reward from it, then they are more likely to view it is a positive experience. If, however, there are no rewards or gains to be achieved from the process, then it is unlikely that she will see it positively.

Sexuality and the menopause are inextricably linked to the attitudes and code of behaviour that society imposes on women. If the society does not consider it appropriate that a woman should continue to be sexual in her menopausal years, then those influences may indirectly affect the woman's sexual response. She may think that it is inappropriate to feel sexual or guilty about sexual thoughts and feelings that she may have. If the woman is so indoctrinated to believe that the sexual experience will be unpleasant, painful and not worth the effort or investment, then it most likely will turn out to be the case.

Western culture's idealisation of youthful beauty where sex is predominantly defined as the preserve of youth, and where the sexual experiences of the middle-aged and elderly continue to be clouded in restrictive myths and prejudice, constantly reminds women that a perfect body is required for physical attractiveness, this can lead to diminished self esteem for all those who suffer from a discrepancy between the ideal and the actual (Weijmar 1991). The ideal approach for women who are finding the menopausal transition difficult is a collaborative effort between physicians and therapists. The context in which a woman experiences her menopause and her sexuality is often more important than the physiological outcome. Further studies are needed and more open discussion of this topic will hopefully lead to heightened interest and awareness, as well as more clinical and basic science research. 


\section{$\underline{\text { References }}$}

American Psychiatric Association (1987) DSM-IV: Committee on nomenclature and statistics. Diagnostic and statistical manual of mental disorders. $3^{\text {rd }}$ Edition. Washington D.C., American Psychiatric Association.

American Psychiatric Association (1994) DSM-IV: Committee on nomenclature and statistics. Diagnostic and statistical manual of mental disorders. $4^{\text {th }}$ Edition. Washington D.C., American Psychiatric Association.

Bancroft J (1989) Human Sexuality and its problems. Edinburgh, Churchill Livingstone.

Basson R et al (2000) Report on the international consensus development conference on female sexual dysfunction: Definitions and classifications. The Journal of Urology. Vol 163 p 888-893.

Basson R. (2000) The female sexual response: A different model. Journal of Sex \& Marital Therapy. No 26 p 51-65.

Berman J and Goldstein I (2001) Female Sexual Dysfunction. Urologic Clinics of North America. Vol 28 No 2 p 410.

Beyene Y and Martin C (2000) Menopausal experiences and bone density of Mayan woman in Yucatan Mexico. American Journal of Human Biology. Vol 13 p 505-511.

Bulbeck C (2001) Speaking menopause: Intersections between Asian and Western medical discourses. Issue 5. Web page:

http//wwwsshe.murdoch.edu.au/intersections/issue5/bulbeck2.html

Edwards GJ and Anderson I (1999) Systematic review and guide to selection of serotonin reuptake inhibitors. Drugs. Vol 57 507-533. Chester, Adis International.

Flagg F (1988) Fried green tomatoes at the Whistle Stop Café. New York: McGraw-Hill. Hunter M (1996) Depression and the menopause. BMJ. Vol 313 p 1217-1218.

Kaufert PA (1982) Anthropology and the menopause: The development of a theoretical framework. Maturitas 4, p 181-193.

Klein P et al (1999) Mood and Menopause. British Journal of Obstetrics and Gynaecology. Vol 106 p 1-4. 
Macleod J Ed (1984) Davidson's principles and practice of medicine. $14^{\text {th }}$ Edition. London, Churchill Livingstone.

Mangum T (1999) Teaching the patient impatience: art, ageing and the medical consumer. The Lancet Vol 354.

Masters WH and Johnson VE (1966) Human sexual response. Boston, Little Brown.

Nicol-Smith L (1996) Causality, menopause, and depression: a critical review of the literature. BMJ. 313 p 1229-1232.

Russell P (1998) Sexuality in the lives of older people. Nursing Standard. Vol 13 No 8 p 49-56.

Rice PL (1995) Pog laus, tsis coj khaub ncaws lawm: The menopause in Hmong Women. Journal of Reproductive and Infant Psychology, special issue. Vol 13 p 79-92.

Riley AJ (1991) Sexuality and the menopause. Sexual and Marital Therapy. Vol 6, No 2.

Vincent C et al (2001) Sexuality and the older woman - setting the scene. Pennel Paper No $1, \mathrm{p} 1$. Pennel Initiative funded by The Department of Health, Wyeth and the Motorola Foundation.

WHO 2000 Fact sheet No 252. June 2000. Women, Ageing and Health. Geneva, WHO Press Office. 